\title{
Kidney function in a selected lithium population
}

\author{
A prospective, controlled, lithium-withdrawal study
}

\author{
H. Bendz \\ Dept. of Psychiatry (Head: Prof. Jan-Otto Ottosson, \\ M.D.), Sahlgrenska Hospital, University of \\ Gothenburg, Sweden, and Clinical Studies Unit for \\ Affective Disorders (Director: Prof. John Greden, \\ M.D.), Dept. of Psychiatry, University of Michigan \\ Medical Center, Ann Arbor, U.S.A.
}

\begin{abstract}
Forty-six lithium (Li) patients who had been on Li for about 1-11 years were studied while on $\mathrm{Li}$ and after about 3 months ( 7 weeks -26 months) off $\mathrm{Li}$. Kidney function was compared between patients on $\mathrm{Li}$ and the same patients off $\mathrm{Li}$, and, in 32 matched pairs, between patients on and off $\mathrm{Li}$ and psychiatric controls. Urine osmolality (U-osmol) was significantly lower, urine volume higher in patients on $\mathrm{Li}$ than in controls. Measures of both glomerular and tubular function improved when Li-patients discontinued medication. U-osmol remained somewhat lower than in controls and was negatively correlated with time-on-Li. Although serum creatinine was somewhat higher in $\mathrm{Li}$-patients off $\mathrm{Li}$ than in controls, clearance values were not different between the two groups. Long-term lithium treatment causes a permanent reduction of tubular function. Time-on- $\mathrm{Li}$ is a risk factor. In this population the reduction was clinically insignificant. In addition, $\mathrm{Li}$ treatment causes a reversible reduction of both tubular and glomerular function. The results can probably be generalized to other outpatient Li populations with the same time-on-Li and with U-osmol below $800 \mathrm{mOsm} / \mathrm{kg}$ during ongoing treatment.
\end{abstract}

Received April 27, 1985; accepted for publication May 16, 1985

This is the third paper reporting on a study of lithium (Li) treated patients, triggered by alarming reports in 1977 by Hestbech (1) and Hansen (2), indicating that long-term Li-treatment might cause irreversible renal damage. The first two papers gave a cross-sectional view of patients treated at the Sahlgrenska Hospital in Gothenburg, Sweden (3) and critically surveyed a number of studies pertinent to the subject matter (4). The present paper gives data on a selected group of patients from the Sahlgrenska Hospital (hospital 1) and from the Rảlambshov Hospital in Stockholm, Sweden (hospital 2).

The aim of the present paper is to answer the following questions:
1. Does long-term Li treatment in nontoxic doses cause a permanent disturbance of tubular or glomerular function?

2. Is there a relationship between such a disturbance and treatment variables?

\section{Design}

The investigation started in March, 1978, at the Sahlgrenska Hospital and was continued in 1979 at the Rảlambshov Hospital where it was closed in May, 1982. All patients except one were outpatients, 124 at Sahlgrenska, 38 at Rålambshov. The former group has been previously described in detail (1). 
Table 1

The total Li population and the matched group. Demographic and clinical characteristics

\begin{tabular}{|c|c|c|c|c|}
\hline & \multirow{2}{*}{ Original group } & \multirow{2}{*}{ Withdrawal group } & \multicolumn{2}{|c|}{ Matched group } \\
\hline & & & Li-patients & Controls \\
\hline$n$ & 162 & 46 & \multicolumn{2}{|c|}{32} \\
\hline Sex $M / F \%$ & $36 / 64$ & $35 / 65$ & \multicolumn{2}{|c|}{$31 / 69$} \\
\hline \multirow[t]{2}{*}{ Age (years) } & $49 \pm 15$ & $49 \pm 15$ & $49 \pm 16$ & $49 \pm 16$ \\
\hline & $(20-77)$ & $(20-74)$ & $(23-74)$ & $(23-78)$ \\
\hline \multicolumn{5}{|l|}{ Diagnosis $\%$} \\
\hline UP & 31 & 33 & 38 & 44 \\
\hline $\mathrm{BP}$ & 51 & 48 & 47 & 38 \\
\hline $\mathrm{CP}$ & 12 & 4 & 6 & 9 \\
\hline $\mathrm{SCH}$ & 3 & 4 & 6 & 6 \\
\hline US & 3 & 11 & 3 & 3 \\
\hline Time-on-Li (months) & $68 \pm 37$ & $61 \pm 35$ & $68 \pm 33$ & \\
\hline$(n=159)$ & $(2-160)$ & $(8-136)$ & $(25-136)$ & \\
\hline *Average S-Li (mEq/I) & $0.77 \pm 0.11$ & $0.75 \pm 0.11$ & $0.74 \pm 0.09$ & \\
\hline & $(0.6-1.1)$ & $(0.6-1.1)$ & $(0.6-0.9)$ & \\
\hline \multicolumn{5}{|l|}{ *Number of patients with } \\
\hline $\max \mathrm{S}-\mathrm{Li}>1.5 \mathrm{mEq} / 1$ & 9 & 3 & 1 & \\
\hline${ }^{*}$ Range $>1.5 \mathrm{mEq} / 1$ & $1.6-3.4$ & $1.7-3.4$ & 2.0 & \\
\hline
\end{tabular}

* Only hospital 1.

$\mathrm{UP}=$ unipolar affective disorder; $\mathrm{BP}=$ bipolar affective disorder; $\mathrm{CP}=$ cycloid psychosis; $\mathrm{SCH}=$ schizophrenia; US = unspecified affective disorder.

Of the total of 162 patients 40 were selected for $\mathrm{Li}$ withdrawal according to the following criteria: 1) reduced kidney function, defined as urinary osmolality (U-osmol) below $800 \mathrm{mOsm}$ / $\mathrm{kg} \mathrm{H}_{2} \mathrm{O}$ in a desamine-8-D-arginin vasopressin (DDAVP) test (3) or glomerular filtration rate (GFR) below -2 SD for age as measured by the ${ }^{51} \mathrm{Cr}$-EDTA (ethylenediaminetetra-acetic acid) clearance method $(5,6)$; 2) no psychiatric contraindication for withdrawal; 3) patient consents to withdrawal. We studied renal function immediately before $\mathrm{Li}$ withdrawal (on $\mathrm{Li}$ ), and at the end of a $\mathrm{Li}$ withdrawal period which should be 3 months (off Li). During that period the patients were treated by their usual doctor with medication according to clinical needs. In addition, six patients requested that, in spite of normal renal findings, $\mathrm{Li}$ should be discontinued. They were also included in the study.

Matching. Controls were not necessarily candidates for $\mathrm{Li}$ treatment but matched with a suitable Li-patient according to the following criteria: age \pm 7 years; sex; hospital; diagnosis, where unipolar affective disorder (UP), bipolar affective disorder (BP), and cycloid psychosis (CP) were combined as one "affective" diagnosis, while schizophrenia ( $\mathrm{SCH}$ ) and unspecified affective disorder (US) remained separate. Exclusion criterion was a history of $\mathrm{Li}$ treatment of any duration. Thirty-two patients who had been on Li for more than 2 years were included in the matching procedure with control subjects. Table 1 gives characteristics of the original group, the withdrawal group, and the matched group.

Time-off-Li. Five of the 46 withdrawal patients had their Li-free period shortened to less than 3 months. One relapsed and resumed $\mathrm{Li}$ after 7 weeks, and in four, the time interval between on and off $\mathrm{Li}$ was 10-12 weeks. Among the remaining 41,24 had a time interval of 3-4 months, eight had 4-6 months and nine had 7-26 monhts. One patient who discontinued Li before entering 
Table 2

Intraindividual comparison of renal function tests and weight on and off $\mathrm{Li}$

\begin{tabular}{|c|c|c|c|c|c|c|}
\hline \multirow[b]{2}{*}{$\begin{array}{l}\text { Unit } \\
\text { Reference } \\
\text { level }\end{array}$} & \multirow{2}{*}{$\begin{array}{c}\text { S-Cre } \\
\text { umol/1 } \\
(\mathrm{M}<120 ; \\
\mathrm{F}<110)\end{array}$} & Cre clearance & ${ }^{51} \mathrm{Cr}-\mathrm{EDTA}$ & \multirow{2}{*}{$\begin{array}{c}\text { U-osmol } \\
\text { mOsm } / \mathrm{kg} \mathrm{H}_{2} \mathrm{O} \\
(\geq 800)\end{array}$} & \multirow{2}{*}{$\begin{array}{c}V u \\
1 / 24 h \\
(\leq 3)\end{array}$} & \multirow{2}{*}{$\begin{array}{c}\text { Weight } \\
\mathrm{kg}\end{array}$} \\
\hline & & $(\geq 90)$ & $\begin{array}{l}\text { (age- and } \\
\text { sex-related) }\end{array}$ & & & \\
\hline$n$ & 42 & 42 & 19 & 45 & 42 & 38 \\
\hline On $\mathrm{Li}$ & $\begin{array}{c}86.3 \\
(50-130)\end{array}$ & $\begin{array}{c}93.3 \\
(50-180)\end{array}$ & $\begin{array}{c}79.7 \\
(41-106)\end{array}$ & $\begin{array}{c}674.3 \\
(301-1,013)\end{array}$ & $\begin{array}{c}2.5 \\
(1.2-6.3)\end{array}$ & 70 \\
\hline Off $\mathrm{Li}$ & $\begin{array}{c}90.6 \\
(50-190)\end{array}$ & $\begin{array}{c}96.5 \\
(19-173)\end{array}$ & $\begin{array}{c}88.2 \\
(43-140)\end{array}$ & $\begin{array}{c}750.8 \\
(210-1,116)\end{array}$ & $\begin{array}{c}1.9 \\
(1.7-6.3)\end{array}$ & 68 \\
\hline Mean diff. $\pm S D$ & $-4.3 \pm 26.5$ & $-3.2 \pm 37.3$ & $-8.5 \pm 16.5$ & $-76.5 \pm 134.8$ & $0.6 \pm 0.9$ & 2 \\
\hline$t$ & 1.06 & 0.55 & 2.22 & 3.81 & 4.31 & 3.57 \\
\hline$P$ & NS & NS & $*$ & $* * *$ & $* * *$ & $* * *$ \\
\hline \multicolumn{7}{|c|}{$\begin{array}{l}\text { Number of patients } \\
\text { beyond reference range }\end{array}$} \\
\hline on $\mathrm{Li}$ & 2 & 20 & 5 & 37 & 10 & \\
\hline off $\mathrm{Li}$ & 4 & 19 & 3 & 26 & 5 & \\
\hline
\end{tabular}

Cre = creatinine $\mathrm{U}$-osmol $=$ urinary osmolality; $\mathrm{Vu}=$ volume of urine.

the study, participated only in the matched comparison.

The withdrawal group and the matched group are representative of the original population on several variables that may be, or are known to be, related to renal function. The only Li-patient in the matched group who had a maximum S-Li above $1.5 \mathrm{mEq} / \mathrm{l}$ showed at that time no clinical signs of toxicity. Results from the comparison between the Li-patients and controls can, therefore, be generalized to those of the original population of $162 \mathrm{Li}$-patients who fulfilled the inclusion criteria.

\section{Material}

\section{Patients}

Diagnostic criteria have been given previously (3).

Somatic disease. One of the 46 patients admitted to insignificant phenacetin consumption. Twenty-two had a history of clinically significant, physical disease. Ten of them had had lower tract urinary infection, four of these, in addition, cardiosclerosis. One patient had cardiosclerosis and a silent urinary tract infection at the examination off $\mathrm{Li}$. One had a history of kidney stones on two occasions, 5 and 15 years ago; intravenous pyelogram performed 1 year before participation in this study was normal. One had a kidney stone half a year before she entered the study, and a history of recurrent cystitis. One had a history of what she believed had been an attack of acute glomerulonephritis 15 years before. One had an attack of pyelitis 1 month before she entered the study, and one had an attack between the first and second kidney function examination. One of them had a significant bacteriuria at the second examination with no clinical signs of renal infection. Another patient with no history of cardiovascular or renal disease had bacteriuria and hematuria at the time of the second kidney function tests. She had no symptoms of renal infection, and erythrocyte sedimentation rates were normal. Two had a diagnosis of hypertension (presently with normal blood pressure on a diuretic), one of them had also hyperlipemia and Parkinson's disease. One had a diagnosis of diabetes mellitus (treated perorally), and one had a neurological disorder, probably multiple sclerosis. Data on cardiovascular disease were missing in two patients. 
Table 3

Comparison of renal function tests between patients on $\mathrm{Li}$ and matched controls

\begin{tabular}{|c|c|c|c|c|c|}
\hline & \multirow{2}{*}{$\begin{array}{c}\mathrm{S}-\mathrm{Cre} \\
\mu \mathrm{mol} / 1\end{array}$} & Cre clearance & SICr-EDTA & \multirow{2}{*}{$\begin{array}{c}\text { U-osmol } \\
\text { mOsm/kg H}{ }_{2} \mathrm{O}\end{array}$} & \multirow{2}{*}{$\begin{array}{c}\mathrm{Vu} \\
1 / 24 \mathrm{~h}\end{array}$} \\
\hline & & \multicolumn{2}{|c|}{$\mathrm{ml} / \mathrm{min} / 1.73 \mathrm{~m}^{2}$} & & \\
\hline$(n)$ & (29) & (15) & (12) & (27) & (19) \\
\hline Mean on $\mathbf{L i}$ & 84 & 90 & 78 & 662 & 2.8 \\
\hline Mean control & 82 & 94 & 86 & 798 & 1.9 \\
\hline Diff. \pm SD & $2 \pm 18$ & $-4 \pm 37$ & $-8 \pm 26$ & $-136 \pm 212$ & $0.9 \pm 1.9$ \\
\hline $\mathrm{t}$ & 0.47 & 0.39 & 1.04 & 3.34 & 1.93 \\
\hline$P$ & NS & NS & NS & ** & * \\
\hline \multicolumn{6}{|c|}{$\begin{array}{l}\text { Number of subjects } \\
\text { beyond reference range }\end{array}$} \\
\hline Li-patients & 1 & 5 & 5 & 23 & 7 \\
\hline Controls & 0 & 6 & 1 & 13 & 3 \\
\hline
\end{tabular}

Abbreviations as in Table 2.

Table 4

Comparison of renal function tests between patients off $\mathrm{Li}$ and matched controls

\begin{tabular}{|c|c|c|c|c|c|}
\hline \multirow[b]{3}{*}{ (n) } & \multirow{3}{*}{$\begin{array}{c}\begin{array}{c}\text { S-Cre } \\
\mu \mathrm{mol} / \mathrm{I}\end{array} \\
(29)\end{array}$} & Cre clearance & ${ }^{5} \mathrm{Cr}$-EDTA & \multirow{3}{*}{$\begin{array}{c}\begin{array}{c}\text { U-osmol } \\
\mathrm{mOsm} / \mathrm{kg} \mathrm{H} \mathrm{H}_{2} \mathrm{O}\end{array} \\
(27)\end{array}$} & \multirow{3}{*}{$\begin{array}{c}\mathrm{Vu} \\
1 / 24 \mathrm{~h}\end{array}$} \\
\hline & & \multicolumn{2}{|c|}{$\mathrm{ml} / \mathrm{min} / 1.73 \mathrm{~m}^{2}$} & & \\
\hline & & (15) & $(26)$ & & \\
\hline Mean off $\mathrm{Li}$ & 93 & 96 & 94 & 730 & 2.1 \\
\hline Mean control & 82 & 96 & 90 & 798 & 2.1 \\
\hline Diff. $\pm S D$ & $11 \pm 30$ & 0 & $4 \pm 28$ & $-68 \pm 206$ & $0.0 \pm 1.4$ \\
\hline $\mathrm{t}$ & 2.03 & 0.33 & 0.79 & 1.71 & \\
\hline$P$ & $*$ & NS & NS & $*$ & \\
\hline \multicolumn{6}{|c|}{$\begin{array}{l}\text { Number of subjects } \\
\text { beyond reference range }\end{array}$} \\
\hline Li-patients & 4 & 8 & 6 & 19 & 2 \\
\hline Controls & 0 & 6 & 1 & 13 & 3 \\
\hline
\end{tabular}

Abbreviations as in Table 2.

Thyroid function in Li-patients and controls. Five patients were on thyroid substitution when they entered the study. One of these had been strumectomized 25 years before, and another one had a slightly elevated level of thyroid stimulating hormone (TSH). Three unsubstituted patients had high levels of TSH and three had slightly elevated levels.

We did not routinely do thyroid function tests in the controls but 35 of 36 examined controls had a normal TSH. In one, TSH was increased to 23 IU (normal is $<15$ ) and thyroxin level decreased. None of the controls had clinical signs of thyroid dysfunction.

Maximal 12 h serum $L i$ ( $S-L i$ ). Nine patients from hospital 1 had had at least one episode of S-Li >
$1.5 \mathrm{mEq} / 1$. S-Li from hospital 2 was not included in the analysis because of irregularities in the adherence to the $12 \mathrm{~h}$ rule. The policy since may years, however, of the physician in charge of most of the Li-patients, was to keep $\mathrm{Li}$ dose as low as possible without relapse.

\section{Controls}

Data from 32 controls were used in the matched comparison with Li-patients. Twenty-three controls, the majority being inpatients, came from hospital 1 , and nine, the majority being outpatients, from hospital 2 (Table 1). Diagnostic criteria were the same as for the patients. 
Table 5

Simple correlations for Li-patients on and off $\mathrm{Li}$ and controls

\begin{tabular}{|c|c|c|c|c|}
\hline \multirow{2}{*}{ Renal function parameter } & \multirow{2}{*}{$\begin{array}{l}\text { Average S-Li } \\
\text { (hospital 1) }\end{array}$} & \multicolumn{2}{|c|}{ Lithium patients } & \multirow{2}{*}{$\begin{array}{l}\text { Controls } \\
\text { Age }\end{array}$} \\
\hline & & Time-on-Li & Age & \\
\hline${ }^{*} \mathrm{~S}-\mathrm{Cre} \mathrm{I}$ & 0.18 (NS) & -0.04 (NS) & 0.18 (NS) & \\
\hline$n$ & 33 & 43 & 44 & \\
\hline${ }^{*}$ S-Cre II & 0.10 (NS) & 0.02 (NS) & -0.04 (NS) & 0.15 (NS) \\
\hline$n$ & 32 & 42 & 43 & 57 \\
\hline Cre clear. I & $-0.15(\mathrm{NS})$ & -0.14 (NS) & -0.23 (NS) & \\
\hline$n$ & 32 & 44 & 45 & \\
\hline -Cre clear. II & -0.25 (NS) & -0.10 (NS) & $-0.43\left({ }^{* *}\right)$ & $-0.20(\mathrm{NS})$ \\
\hline$n$ & 32 & 42 & 43 & 27 \\
\hline${ }^{51} \mathrm{Cr}$-EDTA clear. I & $-0.11(\mathrm{NS})$ & -0.27 (NS) & $-0.45(* *)$ & \\
\hline$n$ & 16 & 18 & 19 & . \\
\hline${ }^{51} \mathrm{Cr}$-EDTA clear. II & $-0.13(\mathrm{NS})$ & -0.25 (NS) & $-0.57(* * *)$ & $-0.67(* * *)$ \\
\hline$n$ & 29 & 41 & 42 & 47 \\
\hline U-osmol I & -0.20 (NS) & $-0.39(* *)$ & $-0.41(* *)$ & \\
\hline$n$ & 33 & 44 & 45 & \\
\hline U-osmol II & $-0.13(\mathrm{NS})$ & $-0.57(* * *)$ & $-0.34\left(^{*}\right)$ & $-0.41(* *)$ \\
\hline$n$ & 32 & 45 & 46 & 47 \\
\hline Vu I & $-0.26(\mathrm{NS})$ & $0.31\left(^{*}\right)$ & -0.10 (NS) & \\
\hline$n$ & 33 & 44 & 45 & \\
\hline Vu II & 0.20 (NS) & 0.27 (NS) & -0.7 (NS) & 0.03 (NS) \\
\hline$n$ & 32 & 42 & 43 & 33 \\
\hline
\end{tabular}

* I $=$ on $\mathrm{Li}$.

II $=$ off $\mathbf{L i}$.

Abbreviations as in Table 2.

\section{Clinical and laboratory methods}

All patients and controls were examined by me or some other experienced psychiatrist. We examined them according to a protocol, described in detail elsewhere (3). Some of them refused one or other of the kidney function tests. Only after a while did we include ${ }^{51} \mathrm{Cr}$ EDTA clearance in all patients on $\mathrm{Li}$ scheduled for $\mathrm{Li}$ withdrawal. ${ }^{51} \mathrm{Cr}$-EDTA clearance values from before the change were excluded from the statistical analysis to avoid selecting a subgroup of patients with low GFR. In contrast, all patients off $\mathrm{Li}$ were routinely scheduled for ${ }^{\mathrm{I}} \mathrm{Cr}$ EDTA clearance. Consequently, all those values were included in the statistical analysis, when possible. In patients from hospital 2 the DDAVP-test and ${ }^{51} \mathrm{Cr}$-EDTA clearance were done on the same day, and calcium was excluded among electrolytes. With a few exceptions, body position during ${ }^{51} \mathrm{Cr}$-EDTA clearance was always the same - lying or sitting - on and off $\mathrm{Li}$ and between Li-patients and matched controls.

Statistics. (In many cases - because of unsystematically missing data - $n$ for a given statistic is smaller than the actual number of patients or controls.)

1) Paired t-test comparing 5 measures of renal function on and off $\mathrm{Li}$ in the same patients ( $n$ $=45$ ); one-tailed, under the assumption of reduced function on $\mathrm{Li}$. The following were measures of renal function: serum creatinine (S-Cre), $24 \mathrm{~h}$ endogenous creatinine clearance

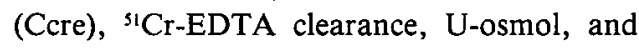
$24 \mathrm{~h}$ urine volume $(\mathrm{Vu})$.

2) Paired t-test, comparing the 5 measures of 
Table 6

Correlation between time-off- $\mathrm{Li}$ and relative change in renal function

\begin{tabular}{lccc}
\hline & Diff ratio & \multicolumn{2}{c}{ Diff ratio } \\
& $n$ & \multicolumn{2}{c}{$r$} \\
\hline S-Cre & 44 & -0.11 & -0.06 \\
Cre clearance & 42 & -0.09 & -0.12 \\
S1Cr-EDTA clearance & 19 & -0.05 & -0.06 \\
U-osmol & 44 & $0.38^{*}$ & $0.36^{*}$ \\
Vu & 42 & -0.06 & 0.00 \\
\hline
\end{tabular}

$* P<0.05$.

Abbreviations as in Table 2.

renal function in patients on $\mathrm{Li}$ and matched controls $(n=31)$, and, between patients off $\mathrm{Li}$ and matched controls $(n=32)$; one-tailed, under the assumption of reduced function in Li-patients.

3) a. Correlation coefficients in Li-patients on $\mathrm{Li}$ $(n=45)$, and off $\operatorname{Li}(n=46)$, and in controls ( $n$ $=59$ ). Independent variables were average$\mathrm{S}$-Li-during-time-on-Li (average $\mathrm{S}-\mathrm{Li}$ ), timeon-Li, and age. Dependent variables were the 5 measures of renal function on and off $\mathrm{Li}$.

b. Correlation coefficients in Li-patients ( $n$ $=45$ ). Independent variable was time-off-Li, dependent was change in renal function, calculated as 1) the ratio between values off and on $\mathrm{Li}$ (ratio S-Cre, etc.), and 2) the difference between those values (diff S-Cre, etc.) For diff $\mathrm{U}$-osmol and ratio U-osmol, time-on-Li was also used as independent variable.

c. Multiple regression analyses in Li-patients $(n=45)$. Independent variables were time-off- $\mathrm{Li}$ and time-on-Li, dependent were diff and ratio U-osmol one at a time.

4) a. Multiple regression analysis, in patients off Li $(n=29)$, using sex, age, diagnosis, timeon- $\mathrm{Li}$ and average $\mathrm{S}-\mathrm{Li}$ as independent variables and renal function parameters as dependent variables one at a time. To increase homogeneity, patients with a diagnosis of $\mathrm{CP}, \mathrm{SCH}$ and US were excluded from this and the following analyses. At step one, sex, age, and diagnosis were entered. At step two, time-on- $\mathrm{Li}$ and average $\mathrm{S}-\mathrm{Li}$ were added.

b. Multiple regression analysis in patients off $\mathrm{Li}(n=37)$, identical to $4 \mathrm{a}$ with the exclusion of average $\mathrm{S}-\mathrm{Li}$ which was missing in patients from hospital 2 .
5) Multiple regression analysis in matched groups off $\mathrm{Li}(n=32)$, using age and timeon- $\mathrm{Li}$ as independent variables and the difference in renal function between Li-patient and control, each parameter one at a time, as dependent variable.

6) In order to test the appropriateness of the straight line model and the possibility of an interaction between age and time-on-Li we did the following tests, using U-osmol in patients off $\mathrm{Li}$ as dependent variable $(n=37)$ :

a. A residual analysis, plotting residuals against time-on- $\mathrm{Li}$ (test for deviance from the straight line model).

b. Two multiple regression analyses with sex, age, diagnosis, and time-on-Li (the latter unsquared in the first analysis, squared in the

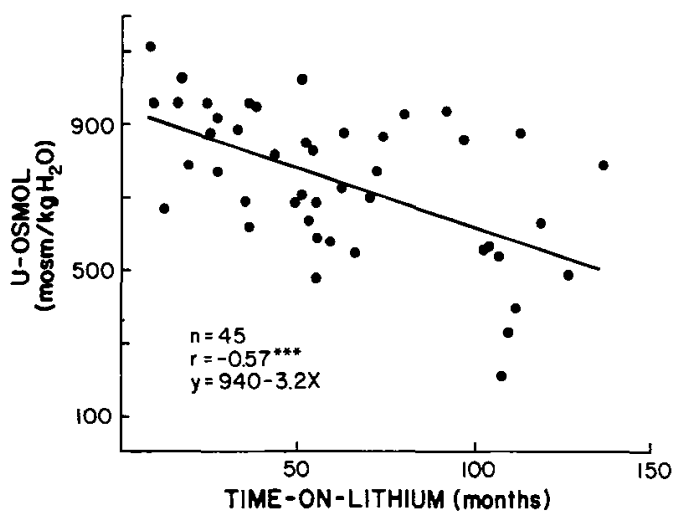

Fig. 1. Correlation between maximum urine osmolality off $\mathrm{Li}$ and time-on-Li. Least square regression line.



Fig. 2. Correlation between absolute change in maximum urinary osmolality and time-off-Li. Least square regression line. 
second analysis) as independent variables (test for curvilinearity).

c. A covariance analysis the sample split in two age groups, one over 40 , one under 40 (test for interaction between age and time-onLi).

Statistical significance is $*=P<0.05,{ }^{* *}=P$ $<0.01,{ }^{* * *}=P<0.001$.

The investigation was approved by the Ethics Committee at the Medical Faculty in Gothenburg and at the Karolinska Institute, Stockholm.

\section{Results}

1) Intraindividual comparison of renal function tests and weight on and off $\mathrm{Li}$ (Table 2).

Serum creatinine and creatinine clearance did not change significantly although both increased. The number of patients below reference range changed accordingly.

${ }^{5 \prime} C r$-EDTA clearance increased significantly. The number of patients below reference range for age and sex decreased. With all data on ${ }^{51} \mathrm{Cr}$-EDTA clerance in patients off $\mathrm{Li}$ included, seven of 42 patients were below normal.

Maximal urine osmolality increased $76 \mathrm{mOsm} /$ $\mathrm{kg}$. The number of patients below 800 $\mathrm{mOsm} / \mathrm{kg}$ (cut-off level for this study) decreased.

Urine volume decreased 0.61 . The number of patients with over 31 (by definition the level of polyuria) also decreased.

Weight decreased significantly.

2) Paired comparison of renal function tests between patients on $\mathrm{Li}$ and matched controls (Table 3).

Serum creatinine, creatinine clearance and ${ }^{5} C r$-EDTA clearance did not differ significantly between Li-patients and controls, while maximum urine osmolality was 136 mOsm lower and urine volume $0.9 \mathrm{I}$ higher, in Lipatients than in controls.

Paired comparison of renal function tests between patients off $\mathrm{Li}$ and matched controls (Table 4).
Table 7

Multiple stepwise regression analysis of renal function parameters on age, sex, diagnosis, and time-on- $\mathrm{Li}$ for patients off $\mathrm{Li}$

$$
\begin{array}{ll}
\begin{array}{l}
\text { S-Cre } \\
(n=36)
\end{array} & \mathrm{y}=138-7 \mathrm{x}_{1}-0.4 \mathrm{x}_{2}-9 \mathrm{x}_{3} \\
& \mathrm{R}^{2}=0.06 \\
& \mathrm{SE}=25.7 \\
& \mathrm{~F}(3,35)=0.7 \mathrm{NS} \\
\text { Cre clearance } & \mathrm{y}=127-24 \mathrm{x}_{1}{ }^{* *}-0.3 \mathrm{x}_{2}+12 \mathrm{x}_{3} \\
(n=36) & \mathrm{R}^{2}=0.41 \\
& \mathrm{SE}=22.4 \\
& \mathrm{~F}(3,35)=7.6^{* * *} \\
& \\
\text { 51Cr-EDTA } & \mathrm{y}=131-10 \mathrm{x}_{1}-0.6 \mathrm{x}_{2}+3 \mathrm{x}_{3} \\
\text { clearance } & \mathrm{R}^{2}=0.31 \\
(n=33) & \mathrm{SE}=18 \\
& \mathrm{~F}(3,32)=4.3^{*} \\
& \mathrm{y}=1,278-98 \mathrm{x}_{1}-3 \mathrm{x}_{2}-43 \mathrm{x}_{3}- \\
\text { U-Oosmol } & 2 \mathrm{x}_{4}^{* *} \\
(n=37) & \mathrm{R}^{2}=0.41 \\
& \mathrm{SE}=141 \\
& \mathrm{~F}(4,36)=5.7^{* *} \\
& \mathrm{y}=1,378-41 \mathrm{x}_{1}-0.6 \mathrm{x}_{2}-365 \mathrm{x}_{3} \\
& \mathrm{R} 2=0.04 \\
& \mathrm{SE}=943 \\
(n=36) & \mathrm{F}(3,35)=0.49 \mathrm{NS} \\
&
\end{array}
$$

$\mathrm{R}^{2}=$ determination coefficient; $\mathrm{SE}=$ standard error of the regression; $x_{1}=$ sex, $x_{2}=$ age, $x_{3}=$ diagnosis, $x_{4}=$ time-on-Li. Regression equations are the final ones.

Abbreviations as in Table 2.

Serum creatinine was somewhat higher, and maximal urine osmolality $68 \mathrm{mOsm} / \mathrm{kg}$ lower in Li-patients than in controls. Nineteen $(59 \%)$ of the Li-patients and $13(41 \%)$ of the controls were below $800 \mathrm{mOsm} / \mathrm{kg}$.

Creatine clearance, ${ }^{s /} \mathrm{Cr}$-EDTA clearance, and urine volume did not differ significantly between $\mathrm{Li}$-patients and controls.

3) Simple correlations on and off $\mathrm{Li}$ (Tables 5 and 6).

Average $\mathrm{S}-\mathrm{Li}$ did not correlate significantly with any of the renal parameters.

Time-on- $\mathrm{Li}$ correlated significantly with $\mathrm{U}$-osmol and $\mathrm{Vu}$ in patients on $\mathrm{Li}$, and with $\mathrm{U}$-osmol (Fig. 1) but not with $\mathrm{Vu}$ in patients off Li. It did not correlate with S-Cre, Cre or ${ }^{\mathrm{St}} \mathrm{Cr}$ EDTA clearance. In addition, it correlated with diff U-osmol ( $\left.n=44, r=-0.38^{*}\right)$ and ratio U-osmol ( $\left.n=44, r=-0.34^{*}\right)$. 


\begin{tabular}{|c|c|c|c|c|c|c|c|c|c|c|c|c|c|}
\hline & & \multicolumn{12}{|c|}{ Matched controls } \\
\hline & & \multicolumn{5}{|c|}{ Diagnosis } & \multicolumn{2}{|c|}{ Renal disease } & \multicolumn{2}{|c|}{$\begin{array}{c}\text { Cardiovascular } \\
\text { disease }\end{array}$} & \multicolumn{3}{|c|}{ Neuroleptic treatment } \\
\hline & & UP & $\mathrm{BP}$ & $\mathrm{CP}$ & US & $\mathrm{SCH}$ & 0 & 1 & 0 & 1 & 0 & 1 & 2 \\
\hline \multicolumn{14}{|c|}{ Diagnosis } \\
\hline \multirow{15}{*}{ 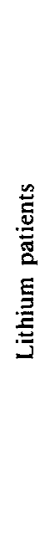 } & UP & 7 & 5 & & & & & & & & & & \\
\hline & $\mathrm{BP}$ & 7 & 7 & 1 & & & & & & & & & \\
\hline & $\mathrm{CP}$ & & & 2 & & & & & & & & & \\
\hline & US & & & & 1 & & & & & & & & \\
\hline & $\mathrm{SCH}$ & & & & & 2 & & & & & & & \\
\hline & Renal disease* & & & & & & & & & & & & \\
\hline & 0 & & & & & & 24 & 2 & & & & & \\
\hline & 1 & & & & & & 3 & 1 & & & & & \\
\hline & Cardiovasuclar disease** & & & & & & & & & & & & \\
\hline & 0 & & & & & & & & 23 & 2 & & & \\
\hline & 1 & & & & & & & & 2 & 2 & & & \\
\hline & Neuroleptic treatment & & & & & & & & & & & & \\
\hline & 0 & & & & & & & & & & & 1 & \\
\hline & 1 & & & & & & & & & & 1 & 20 & 1 \\
\hline & 2 & & & & & & & & & & 1 & 6 & 2 \\
\hline
\end{tabular}

$0=$ None.

1 = Present (for disease).

$1=$ Intermediate between 0 and 2 (for neuroleptics).

$2=\geq 2$ years of neuroleptic treatment.

* Data missing in 2 pairs.

** Data missing in 3 pairs.

Abbreviations as in Table 1.

Time-off- $L i$ correlated significantly with ratio as well as diff U-osmol (Fig. 2).

Age correlated significantly with ${ }^{51} \mathrm{Cr}$-EDTA clearance and $\mathrm{U}$-osmol in patients on and of $\mathrm{Li}$ and in controls. In patients off $\mathrm{Li}$, age correlated significantly also with Ccre.

Multiple regression analyses in $\mathrm{Li}$-patients.

Both time-on-Li and time-off-Li contributed significantly and in opposite directions to the variance in diff U-osmol, while in the case of ratio U-osmol only time-off-Li reached significance as a predictor.

4) Multiple regression analyses off $\mathrm{Li}$ (Table 7). Since, in the first multiple regression analysis, average S-Li did not contribute significantly to the variance in any of the five renal function parameters, we repeated the analysis, excluding average $\mathrm{S}-\mathrm{Li}$. This gave us a larger sample and one variable less to account for. Table 7 shows that only for Ccre and U-osmol did any of the independent variables contribute significantly to the variance. In this model, men had a Ccre $24 \mathrm{ml} / \mathrm{min}$ higher than women, while timeon-Li predicted a decline in U-osmol of 2 $\mathrm{mOsm} / \mathrm{month}$. Within the model, 13 years of Li treatment would, therefore, predict a decline in U-osmol of about $300 \mathrm{mOsm}$. Age too, was a negative predictor of U-osmol without reaching significance and would only contribute another $40 \mathrm{mOsml}$ during the same 13 years.

5) Multiple regression analysis in matched groups.

Time-on- $L i$ contributed significantly to the variance in U-osmol difference between patients off $\mathrm{Li}$ and their matched controls.

6) Additional analysis of U-osmol in patients off $\mathrm{Li}$, including residual analysis, multiple regression analyses (time-on-Li squared and un- 
squared), and analysis of covariance did not indicate any deviation from the straight line model, improvement in linear fit by a curvilinear model ( $\mathrm{R}^{2}$ remained practically unchanged), or in this small sample, interaction between age and duration. The straight line model is therefore appropriate, and the effects of age and time-on-Li probably additive.

\section{Discussion}

\section{Sources of error}

As discussed in a previous paper (3), some of the data retrieved from patient charts were not particularly reliable. This pertains especially to S-Li, while information on doses of $\mathrm{Li}$ and neuroleptics seemed more reliable. In patients from hospital 2, S-Li could not be used for statistical analysis while time-on- $\mathrm{Li}$ and time-on-neuroleptics seemed sufficiently accurate.

Creatinine clearance is a difficult method to use for assessment of glomerular function and served poorly in this study.

Maximal urine osmolality in a real sense is not achieved by using the DDAVP-method. It performs reasonably well, however, for screening purposes, although it tends to underestimate the maximal concentration capacity, especially in the high osmolar range.

In both $\mathrm{Li}$-patients and controls - more so among the former - there were several individuals with a history of physical disease that could influence kidney function. As discussed below, this influence probably does not invalidate the comparison between $\mathrm{Li}$-patients and controls.

By excluding neuroleptic treatment and exact affective diagnosis as matching criteria, the number of matched pairs was increased, but additional uncontrolled sources of variance were simultaneously introduced. It could be argued that diagnosis may affect kidney function. Also, kidney disease and heart disease were not included among the matching criteria. I tried, however, to take all these factors into account when arranging the pairs. Concurrent neuroleptic treatment may not affect renal function (4).
Nevertheless, for neuroleptic treatment each patient and subject was assigned a dummy variable 2,1 or 0 where 2 = treated with neuroleptics of any kind (except for dixyrazim and alimemazin) and any dosage, for altogether 2 years or more during their whole lifetime; only continuous treatment of at least 1 week's duration was included; $0=$ not treated with neuroleptics. $1=$ intermediate between 2 and 0 . Consequently, I was able to take this factor too into account, when arranging the pairs.

Table 8 demonstrates that exact diagnosis, neuroleptic treatment and somatic disease turned out to be rather well matched between the two groups.

In addition, some factors of possible importance for renal function were not accounted for at all, namely number of hospitalizations, medication other than neuroleptics, and duration of psychiatric illness. It is reasonable to believe that affectively ill Li-patients in this study are more heavily weighted on the former two items than are the controls. If anything, that would tend to increase the difference in renal function between the two groups.

On the other hand, more controls than Lipatients were hospitalized at the time of the investigation. If anything, this should give the opposite tendency in the above-mentioned factor.

Thyroid function, also, was not included among matching criteria. Among 32 Li-patients one had an elevated TSH both on and off $\mathrm{Li}$. Among 32 controls one had an elevated TSH. In both cases the corresponding "twin" had a normal TSH.

Everything considered, including the known but quantitatively minor mismatching between the two groups, I conclude that the difference in renal function between Li-patients and controls could be ascribed to the major differentiating variable, namely the $\mathrm{Li}$-treatment.

\section{Renal function}

Bucht \& Wahlin (7) found 8 weeks to be sufficient for maximal restoration of renal function. Tubular function in their patients had improved significantly after 8 weeks off $\mathrm{Li}$ and 
no further improvement was discernible after another 10 months off Li. Our analysis of the effect of time-off-Li gave somewhat different results. We found a significant correlation between time-off- $\mathrm{Li}$ and absolute and relative change in U-osmol (Table 6, Fig. 2). $\mathrm{Vu}$ and ${ }^{51} \mathrm{Cr}$-EDTA clearance, which also improved on $\mathrm{Li}$ withdrawal, showed no significant correlation with time-off-Li. All but five patients had timeoff-Li for 12 weeks or more. The correlation with U-osmol change may therefore indicate that tubular function keeps improving for a long time after Li withdrawal, i.e. for more than 12 weeks. However, the correlation was weak, and as shown in Fig. 2 most of the datapoints piled up in the lower range of time-off-Li where they deviated considerably from the least square regression line.

Serum creatinine was above normal in $4 / 45$ patients off $\mathrm{Li}$. In two of them ${ }^{51} \mathrm{Cr}$-EDTA clearance was normal, and in the other two slightly below normal. In one control S-Cre was borderline high, ${ }^{51} \mathrm{Cr}$-EDTA clearance normal. ${ }^{5 /} \mathrm{Cr}$ EDTA clearance was below normal in $7 / 42$ patients off $\mathrm{Li}$ and borderline low in $1 / 43$ of the controls. None of them had a history of cardiovascular or renal disease (data were lacking for the former in 1, for the latter in 1). Thus, although as a group the Li-patients did not differ from controls there may be individuals who have a slightly reduced glomerular function, not necessarily due to Li treatment.

Urine osmolality was below $800 \mathrm{mOsm}$ in $26 / 45$ $(58 \%)$ patients off $\mathrm{Li}$, and in $18 / 47(38 \%)$ controls. Three of the Li-patients below 800 had a history of cardiovascular or renal disease, or both, while in two data were lacking for both items. Five of the controls below 800 had a history of cardiovascular or renal disease. In one additional control data were missing for cardiovascular disease. Obviously, the use of 800 mOsm as a cut-off point for abnormality is not helpful for the understanding of tubular function. No valid conclusion as to the effect of $\mathrm{Li}$ treatment on tubular function could be drawn from the number of patients below that level. Age is a predictor of U-osmol in patients both on and off $\mathrm{Li}$ and in controls. Hence, the reference range for $U$-osmol should be age-related, as is the reference range for clearance.

Polyuria was present in $24 \%$ of Li-patients on $\mathrm{Li}$, in $12 \%$ off $\mathrm{Li}$, and in $12 \%$ of the controls. This attests to the well-known tendency for $\mathrm{Li}$ to cause an increase in urinary output which reverts to normal once $\mathrm{Li}$ is discontinued. "Normal" (as defined by the control group) still means about $1 / 10$ of patients with polyuria.

\section{Comparison of renal function between Li-patients and controls}

\section{a) This study}

$\mathrm{U}$-osmol and $\mathrm{Vu}$ differed between patients on $\mathrm{Li}$ and controls. When $\mathrm{Li}$ was withdrawn, all renal function parameters but S-Cre indicated a functional improvement, which reached statistical significance for ${ }^{51} \mathrm{Cr}$-EDTA clearance, U-osmol, and $\mathrm{Vu}$, and, resulted in a normalization of the latter. Consequently, the difference in renal function between Li-patients and controls was smaller off than on Li except for S-Cre where the difference increased.

The improvement in U-osmol and $\mathrm{Vu}$ is due to removal of $\mathrm{Li}$-induced vasopressin inhibition and to restoration of the renal medullary osmotic gradient. Decrease in secondary polydipsia may also contribute. Improvement in GFR is presumably secondary to the normalization of water and sodium balance. In only one patient did a considerable polyuria $(6.31 / 24 \mathrm{~h})$ and low U-osmol (330 mOsm) persist after $3^{1 / 3}$ months off $\mathrm{Li}$, indicating the possibility of an irreversible diabetes insipidus-like syndrome. The finding is not an unequivocal proof, however, since U-osmol on $\mathrm{Li}$ was 550 , while $\mathrm{Vu}$ was the same as off $\mathrm{Li}$. The patient had been on Li for 110 months, age was 41 and diagnosis schizophrenia. At the time of the second examination, she had bateriuria and hematuria with no signs or symptoms of upper urinary tract infection. Nevertheless, one explanation for a low U-osmol on the second examination could be a urinary tract disorder. Primary polydipsia also cannot be ruled out.

In contrast to $\mathrm{Vu}, \mathrm{U}$-osmol remained and 
S-Cre emerged significantly different between $\mathrm{Li}$ patients off $\mathrm{Li}$ and controls. The difference in S-Cre was small, however, and only three patients had a value above reference age, while on $\mathrm{Li}$ their $\mathrm{S}-\mathrm{Cre}$ was within normal. The elevated level of $\mathrm{S}$-Cre in $\mathrm{Li}$-patients may be interpreted as a sign of decreased GFR, an interpretation which, however, contradicts the clearance levels. In addition, the change in S-Cre between on an off Li goes in a direction contrary to both Ccre and ${ }^{51} \mathrm{Cr}$-EDTA clearance and to expectations. A reduced glomerular function, therefore, cannot explain the finding. Weight and height off $\mathrm{Li}$ were not significantly different between patients and controls. Thus, difference in body mass cannot explain the difference. Controls were examined after their respective Li-patient, sometimes a couple of years later. No change in laboratory routines took place, however, during the course of the complete study (March 1978 through May 1982). Li-treatment may therefore be a causative factor behind the relative increase in S-Cre, although the evidence is not convincing. Laboratory error or even chance occurrence cannot be ruled out.

\section{b) Other studies}

The results of this study summarized above, confirm some of those published by Bucht $\&$ Wahlin (7) and Vestergaard \& Amdisen (8). Those are the only studies, in addition to this one, that have used a group of Li-patients off $\mathrm{Li}$ for comparison with a control group. In a fourth study by Albrecht (9), where reference values but not controls were used, the patients stayed off $\mathrm{Li}$ for 10 days, which is too short a time for the results to be comparable to the three other studies, where patients were $\mathrm{Li}$-free for 7 weeks to more than 1 year. In (7) and (8), the authors found that in Li-patients who discontinued $\mathrm{Li}$, U-osmol returned towards normal but remained lower than in pre-Li patients (8), other psychiatric patients and healthy controls (7). None of them found a significant change in GFR or S-Cre when $\mathrm{Li}$ was withdrawn, nor any difference in GFR or S-Cre between Li-patients and psychiatric controls. Bucht \& Wahlin found that $\mathrm{Li}$ patients on and off $\mathrm{Li}$ had a significantly higher S-Cre than had normal controls. The explanation for an elevated S-Cre relative to psychiatric controls in our group of patients, but not in others, may be found in methodological differences between the studies. In ours, body mass and sex distribution were similar between the two groups. In the other two studies these factors were not accounted for and could possibly have been distributed by chance in a way which eliminated a difference in S-Cre.

The difference in U-osmol between Li-patients and controls is small and clinically insignificant but theoretically important, since it confirms the hypothesis that Li-treatment may indeed cause permanent damage to the kidneys. However, the finding of a significant positive correlation between time-off-Li and U-osmol change (Table 6, Fig. 2) raises some doubt about this conclusion. It may indicate that with a sufficiently long time-off-Li the difference between $\mathrm{Li}$ patients and controls will disappear. Taking this factor into account in the statistical analysis, however, time-on-Li still remained a significant negative predictor of improvement in tubular function.

\section{Relationship between time-on-Li and renal function}

Further evidence in this study for a causal relationship between $\mathrm{Li}$ treatment and permanently reduced tubular function is the finding of a statistically significant correlation between U-osmol off $\mathrm{Li}$ and time-on-Li, and between U-osmol difference (between Li-patients and controls) and time-on- $\mathrm{Li}$, age held constant in both cases. The various regression analyses indicate the same. In the two comparable studies $(7,8)$, the authors also found a significant correlation between time-on- $\mathrm{Li}$ and U-osmol. One of them (7) found a significant correlation between time-on- $\mathrm{Li}$ and $\mathrm{S}-\mathrm{Cre}$ off $\mathrm{Li}$, as did Vestergaard (10) in patients on Li. We were unable to replicate these latter findings.

As evidenced by Fig. 1, U-osmol seems to be approaching plasma osmolality $(285 \mathrm{mOsm} / \mathrm{kg}$ $\mathrm{H}_{2} \mathrm{O}$ ) when time-on-Li reaches values of about 17 years. However, even if the statistical analysis gives support to the straight line model and the effects of age and time-on-Li seem additive, the 
interpretation nevertheless becomes untenable beyond the range of the data, namely about 13 years of $\mathrm{Li}$ treatment. Whether $\mathrm{Li}$ causes an irreversible and pronounced nephrogenic diabetes insipidus in most patients kept on $\mathrm{Li}$ for a sufficient length of time remains to be investigated.

The mechanism behind the irreversible reduction of tubular function is not understood, although it seems likely that the high $\mathrm{Li}$ concentration in the distal tubule is responsible for the damage (11). The pathological anatomy of the lesion underlying the functional impairment has been repeatedly described $(1,2,12-15)$.

Concerning glomerular function, results are even more benign than for tubular function. The evidence for an irreversible effect of non-toxic Li-treatment is weak and none was added by this study, thereby eroding my own conclusion from a previous paper (4) that Li may damage glomerular function permanently.

\section{Conclusions}

The answers to the initial questions can now be given as follows:

1) $\mathrm{Li}$ in non-toxic doses for up to 13 years caused reversible and irreversible disturbances of renal function in this group of Li-patients. The findings can probably be generalized to other populations of Li-patients fulfilling the same inclusion criteria.

2) The reversible disturbance affects both tubular and glomerular function.

3) The irreversible disturbance affects only tubular function. It is, however, clinically insignificant up to this point in time.

4) Time-on- $\mathrm{Li}$ is a risk factor for tubular function.

5) It also follows that the evaluation of true renal function when Li-patients are on $\mathrm{Li}$ is severely handicapped by the confounding reversible effect of $\mathrm{Li}$ on both glomerular and tubular function.

\section{Acknowledgements}

Due to biological circumstances beyond my control, this onecentre study turned into a two-centre study. Only thanks to the continuous support and help from several colleagues was 1 able to finish it, among whom 1 would like to mention Sven Andersch, Mattias Aurell, Ruth Ettlinger, Jan-Otto Ottosson, Göran Persson, and Lil Träskman-Bendz. The psychiatric record room staff in Gothenburg showed unceasing patience. Favourable working conditions provided by a research fellowship at the Department of Psychiatry, Clinical Studies Unit (CSU), University of Michigan, Ann Arbor, Michigan, also made it possible to analyse and present these data. I particularly thank Bernard Carroll, Michael Feinberg, and John Greden. Pam Flegel (CSU) did the statistical computer work on MIDAS (Michigan Interactive Data Analysis System). Michael Feinberg (CSU) and Ken Guire (Department of Biostatics, School of Public Health, University of Michigan) provided statistical expertise.

\section{References}

1. Hestbech J, Hansen H E, Amdisen A, Olsen S. Chronic renal lesions following long-term treatment with lithium. Kidney Int 1977:12:205-213.

2. Hansen H E, Hestbech J, Olsen S, Amdisen A. Renal function and renal pathology in patients with lithiuminduced impairment of renal concentrating ability. Proc Eur Dial Transplant Assoc 1977:14:518-527.

3. Bendz $H$, Andersch $S$, Aurell $M$. Kidney function in an unselected lithium population. A cross-sectional study. Acta Psychiatr Scand 1983:68:325-334.

4. Bendz $H$. Kidney function in lithium-treated patients: $A$ literature survey. Acta Psychiatr Scand 1983:68:303-324.

5. Granérus G, Aurell $M$. Reference values for ${ }^{5} \mathrm{Cr}$-EDTA clearance as a measure of glomerular filtration rate. Scand J Clin Lab Invest 1981:41:611-616.

6. Askergren A, Brandt R, Gullquist R, Silk B, Strandell T. Studies on kidney function in subjects exposed to organic solvents. IV. Effect on ${ }^{\prime} \mathrm{Cr}$-EDTA clearance. Acta Med Scand 1981:210:373-376.

7. Bucht G, Wahlin A. Renal concentrating capacity in longterm lithium treatment and after withdrawal of lithium. Acta Med Scand 1980:207:309-314.

8. Vestergaard $P$, Amdisen A. Lithium treatment and kidney function. A follow-up study of 237 patients in long-term treatment. Acta Psychiatr Scand 1981:63:333-345.

9. Albrecht J, Kampf D, Müller-Oerlinghausen B. Renal function and biopsy in patients on lithium-therapy. Pharmacopsychiatr 1980:13:228-234.

10. Vestergaard $P$, Amdisen A, Hansen $H$ E, Schou $M$. Lithium treatment and kidney function. A survey of 237 patients in long-term treatment. Acta Psychiatr Scand 1979:60:504-520.

11. Hansen HE. Renal toxicity of lithium. Drugs 1981:22:461476.

12. Hansen H E, Hestbech J, Sørensen J L, Nørgaard K, Heilskov J, Amdisen A. Chronic interstitial nephropathy in patients on long-term lithium treatment. Q $\mathbf{J}$ Med 1979:XLVIII:577-591.

13. Aurell M, Svalander C, Wallin L, Alling C. Renal function and biopsy findings in patients on long-term lithium treatment. Kidney Int 1981:20:663-670. 
14. Walker R G, Bennett W M, Davies B M, Kincaid-Smith P. Address Structural and functional effects of long-term lithium therapy. Kidney Int 1982:21:S13-S19.

15. Walker R G, Davies B M, Holwill B J, Dowling J P, Kincaid-Smith P. A clinico-pathological study of lithium nephrotoxicity. J Chron Dis 1982:35:685-695.

Hans Bendz

Klinik 4

Beckomberga Sjukhus

S-161 04 Bromma

Sweden 